\title{
Influence of Open Alleys in Field Trials Assessing Yield Effects from Fungicides in Corn
}

Paul Vincelli, Department of Plant Pathology, University of Kentucky; and Chad Lee, Department of Plant and Soil Sciences, University of Kentucky

\begin{abstract}
Vincelli, P., and Lee, C. 2015. Influence of open alleys in field trials assessing yield effects from fungicides in corn. Plant Dis. 99:263-266.

Including open alleys at ends of plots is a common practice when fieldtesting foliar fungicides used in corn production. Open alleys facilitate movement of workers and equipment between plots during spray application. Open alleys affect crop yield estimates in small plots typically used in replicated, randomized experimental designs, because of reduced interplant competition. However, no published research has tested whether the alley effect interacts with fungicide to bias the assessment of the agronomic effects of the latter. We tested this hypothesis over 2 years by evaluating yield with and without application of Headline AMP (containing pyraclostrobin and metconazole) plus nonionic surfactant applied once at VT/R1 in 7.6-m plots separated on their ends by $1.5-\mathrm{m}$ alleys free of aboveground vegetation. In each plot, data were collected from seven subplots, each measuring $1.09 \mathrm{~m}$ of row-length and running parallel to the long axis of the plot. Consistent

with previous reports, yields of subplots were substantially higher toward plot ends than in the central areas of plots. Surprisingly, a significant $(P<0.10)$ fungicide $\times$ subplot interaction was observed in both experiments, indicating that the yield response from fungicide depended on subplot position within the plot. However, yield differences due to fungicide were trivial when comparing regression-based yield estimates from all seven subplot positions to those obtained from only the centermost three subplot positions. Our study does not lend support to the hypothesis that the open-alley design creates a meaningful bias in assessment of treatment effects due to foliar fungicides in corn. However, additional research on this question is warranted, given the complexities of comparing results in large-scale plots vs. small plots, the limitations of our study, and the widespread use of fungicides on field corn in the United States.
\end{abstract}

$\mathrm{Q}_{\mathrm{O}} \mathrm{I}$ fungicides provide excellent control of a number of diseases of corn, including gray leaf spot and northern leaf blight, diseases of importance in Kentucky and nearby states. Fungicides in this group also are known to induce a variety of generally positive physiological impacts in plants. These effects may include retardation of leaf senescence by affecting endogenous concentrations of ethylene and cytokinins; shifting the $\mathrm{CO}_{2}$ compensation point in favor of growth; increased host resistance to certain pathogens; and increased plant growth and yield $(4-6,16,17)$. In some field experiments, substantial increases in corn yields can result from the application of strobilurin fungicide in the absence of significant, observable disease $(12,13)$. However, agronomic benefits arising from treatment with a strobilurin fungicide can be highly variable or nonexistent under field conditions $(2,9,11,12)$. Validly designed field experiments are critical for the determination of the possible benefits of foliar fungicides in crop production.

In replicated, randomized field trials, many designs leave $1 \mathrm{~m}$ or more of space free of crop growth between plot ends. These open alleys permit movement of field workers and equipment between plots. The portions of plots adjoining open alleys may be included during harvest of grain from individual plots. Including plot ends in the harvest permits all of what is commonly limited plot space to be used for assessment of treatment effects (7). However, it is well-known that the presence of an open alley can influence the performance of agronomic crops $(1,7)$ due to many environmental factors, including increased penetration of sunlight and air movement and reduced interplant competition for soil moisture and nutrients.

While such "end effects" are well known, a common assumption of field trials is that the effect of an open alley on crop yield is

Corresponding author: P. Vincelli, E-mail: pvincell@uky.edu

Accepted for publication 22 August 2014.

http://dx.doi.org/10.1094/PDIS-04-14-0415-RE

(C) 2015 The American Phytopathological Society uniform across treatments (7). If this assumption is valid, including plot ends in the harvested grain would not compromise assessment of treatment effects. However, this assumption is open to question, as a variety of studies have found interactions of varied treatments with border effects $(1,3,7,8,10,15)$. All of these studies evaluated interactions of alley effects with cultivars, crop maturity group, and irrigation regime. To our knowledge, no published studies have tested whether the open alley influenced the assessment of fungicide effects on agronomic performance in any crop. This question seems important, given that millions of previously untreated hectares of grain crops are now treated annually at least once, and sometimes repeatedly, with products containing $\mathrm{Q}_{\mathrm{O}} \mathrm{I}$ fungicides. Thus, the purpose of this study was to test whether the effect of $Q_{0} I$ fungicide on crop performance differed on plot ends adjoining open alleys vs. plot middles, where conditions more closely simulated commercial production fields.

\section{Materials and Methods}

Plots were sown to the corn hybrid DKC 6544 at 35,000 plants/acre on 6 May 2010 and 9 May 2011 into a Maury silt loam soil planted to soybean in 2009. Plots were fertilized according to university recommendations and irrigated as needed with drip irrigation. Seeded areas of each plot were $9.1 \mathrm{~m}$ long and four rows wide (0.76-m centers), oriented approximately north-south. At V3V4 growth stages, the terminal $0.76 \mathrm{~m}$ of all rows was physically removed by hoeing, creating plots $7.6 \mathrm{~m}$ in length with $1.5-\mathrm{m}$ open alleys between the north and south ends of all plots (Fig. 1). Experimental plots were bordered on their east and west sides by four rows of corn not treated with fungicide. Plots were arranged in a randomized complete block design with six replicates of two treatments: Treated at R1 (2 Jul 2010 or 14 Jul 2011) with 0.88 kg liter/ha of Headline AMP fungicide (a premix of $13.6 \%$ pyraclostrobin and $5.1 \%$ metconazole) plus $0.25 \%$ nonionic surfactant, or untreated. Fungicide was applied using a backpack sprayer fitted with four 8002 nozzles on $0.76-\mathrm{m}$ centers in 140 liter/ha. Plots receiving fungicide treatment were re-randomized in 2011, resulting in distinct randomization layouts in the two years of experimentation. 
Disease severity. At approximately one-half milk-line (R5), the center two rows of each plot were subdivided into seven subplots of $1.09 \mathrm{~m}$ of row-length (positions 1 [southernmost] to 7, see Fig. 1 ), and percent foliar disease was assessed visually on the leaf subtending the ear on five arbitrarily selected plants from each subplot.

Yield. At maturity, all ears were hand-harvested from each row of each subplot position, oven-dried $\left(60^{\circ} \mathrm{C}\right)$, hand-shelled, weighed, and corrected to $15 \%$ moisture content. For each subplot position (position 1 to 7), weights of grain from both rows were summed to represent the yield for that subplot position. Because of variation in row length of plots, the terminal position of each plot row harvested varied from 1.09 to $1.60 \mathrm{~m}$ in length. In all terminal subplots, total length and number of plants were recorded, and yields were corrected to a 1.09-m length.

Data analysis. A split-plot analysis of variance was run to analyze grain yield in PROC GLM of SAS (SAS Institute Inc., Cary,

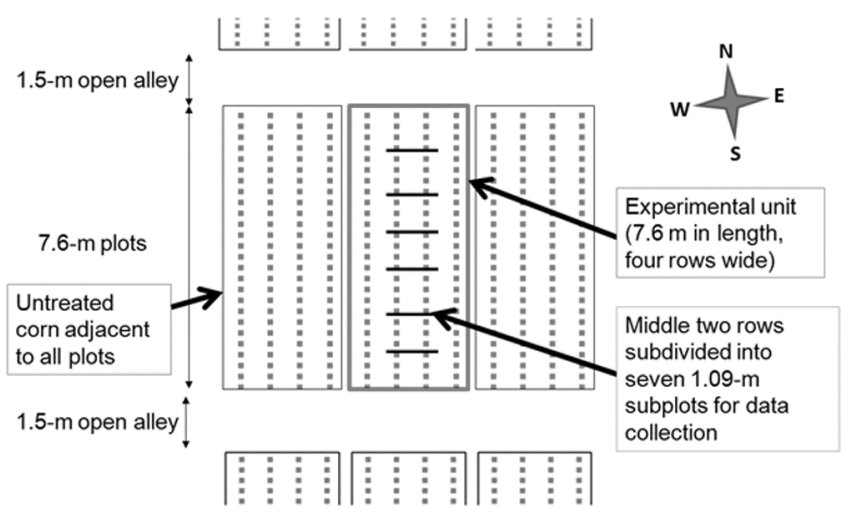

Fig. 1. Layout of plots and subplots.
NC). The whole-plot factor was fungicide treatment, which consisted of Headline AMP vs. untreated control. The split-plot factor was position of the subplots (1 to 7). A polynomial trend analysis was conducted, with factors for fungicide, subplot position, and replicate, with the ANOVA terms for the statistical model listed in Table 1 . There were six replications. Disease levels were extremely low in both years, with $60 \%$ and $>90 \%$ of leaves examined receiving "zeroes" for disease severity in 2010 and 2011, respectively. Therefore, an ANOVA on disease data was not considered appropriate.

\section{Results}

Overall, grain yield was greater in fungicide-treated plots in $2010(P=0.077)$ but not in $2011(P>0.1)$ (Table 1). However, yield was not uniform across all subplot positions: A linear trend of subplot position was significant in $2010(P=0.0274)$ (Table 1$)$, and a quadratic trend was significant in both years $(P<0.0001)$. Interestingly, the interaction of fungicide with subplot position was significant in both 2010 and $2011(P=0.085$ and $P=0.042$, respectively) (Table 1). Based on these results, least-squares regression models were derived that represented these effects (Table 2). Because of the significant fungicide $\times$ subplot interaction, separate models were created for fungicide-treated vs. control treatments. These models were then used to calculate the mean expected grain yield across all subplot positions in both years (Fig. 2). Two key results are illustrated by these regression models:

- Yields were substantially higher toward ends than in the central positions of plots.

- The effect of fungicide on yield varied based on subplot position.

We hypothesized that the estimated yield effect of fungicide might differ using data from all seven subplots vs. the centermost three subplots. This was based on the premise that the central part of plots would be more representative of the true treatment effect than a mean based on all subplots, including those that border the

Table 1. Analysis of variance for grain yield $\left(\mathrm{kg} / \mathrm{m}^{2}\right)$

\begin{tabular}{|c|c|c|c|c|c|c|c|c|c|}
\hline \multirow[b]{2}{*}{ Source } & \multirow[b]{2}{*}{ DF } & \multicolumn{4}{|c|}{2010} & \multicolumn{4}{|c|}{2011} \\
\hline & & Type I SS ${ }^{\mathbf{a}}$ & Mean square & $F$ Value & $\operatorname{Pr}>F$ & Type I SS & Mean square & $F$ Value & $\operatorname{Pr}>F$ \\
\hline Rep & 5 & 0.1299942 & 0.0259988 & 0.82 & 0.5383 & 0.0638562 & 0.0127712 & 1.03 & 0.4110 \\
\hline Fungicide & 1 & 0.0601359 & 0.0601359 & 4.94 & 0.0770 & 0.0023241 & 0.0023241 & 0.11 & 0.7564 \\
\hline Fungicide* rep $^{b}$ & 5 & 0.0609273 & 0.0121855 & 0.39 & 0.8567 & 0.1082217 & 0.0216443 & 1.74 & 0.1399 \\
\hline Subplot & 1 & 0.1614414 & 0.1614414 & 5.11 & 0.0274 & 0.0068473 & 0.0068473 & 0.55 & 0.4613 \\
\hline Subplot ${ }^{2}$ & 1 & 1.5352335 & 1.5352335 & 48.59 & $<0.0001$ & 0.7497821 & 0.7497821 & 60.19 & $<0.0001$ \\
\hline Subplot ${ }^{3 \mathrm{~d}}$ & 1 & 0.0038521 & 0.0038521 & 0.12 & 0.7282 & 0.0118719 & 0.0118719 & 0.95 & 0.3329 \\
\hline Lack of fit ${ }^{\mathrm{e}}$ & 3 & 0.1748828 & 0.0582943 & 1.84 & 0.1487 & 0.0660415 & 0.0220138 & 1.77 & 0.1631 \\
\hline Fungicide*subplot & 1 & 0.0971850 & 0.0971850 & 3.08 & 0.0846 & 0.0537327 & 0.0537327 & 4.31 & 0.0421 \\
\hline 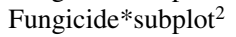 & 1 & 0.0034261 & 0.0034261 & 0.11 & 0.7431 & 0.0182876 & 0.0182876 & 1.47 & 0.2304 \\
\hline 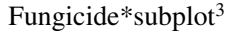 & 1 & 0.0332267 & 0.0332267 & 1.05 & 0.3093 & 0.0151072 & 0.0151072 & 1.21 & 0.2752 \\
\hline Lack of fit & 3 & 0.0184649 & 0.0061549 & 0.19 & 0.8995 & 0.0276144 & 0.0092048 & 0.74 & 0.5330 \\
\hline Error & 60 & 1.8957633 & 0.0315961 & - & - & 0.7474250 & 0.0124571 & - & - \\
\hline
\end{tabular}

a Sums of squares.

b Denominator for $F$-test of "fungicide" effect. For all other $F$-tests, the term designated "error" is the denominator.

c Subplot $\times$ subplot.

d Subplot $\times$ subplot $\times$ subplot.

e The factors subplot ${ }^{4}$, subplot ${ }^{5}$, and subplot ${ }^{6}$ are pooled into this term.

Table 2. Least squares parameters, averaged over replicate, for modeling the effect of fungicide and subplot position on mean grain yield $\left(\mathrm{kg} / \mathrm{m}^{2}\right)$ of $\mathrm{corn}$

\begin{tabular}{|c|c|c|c|c|c|}
\hline \multirow[b]{2}{*}{ Year } & \multirow[b]{2}{*}{ Treatment } & \multicolumn{3}{|c|}{ Parameter estimate (and standard error) } & \multirow[b]{2}{*}{ Regression equation for yield $\left(\mathrm{kg} / \mathrm{m}^{2}\right)^{b}$} \\
\hline & & Intercept & Subplot & Subplot $^{2}$ a & \\
\hline 2010 & Untreated & $\begin{array}{r}2.006(0.088) \\
+0.083(0.084)\end{array}$ & $\begin{array}{l}-0.317(0.045) \\
-0.034(0.019)\end{array}$ & $0.039(0.005)$ & $Y_{\text {untreated }}=2.089-0.351 \mathrm{x}+0.039 \mathrm{x}^{2}$ \\
\hline 2010 & Fungicide & $2.006(0.088)$ & $-0.317(0.045)$ & $0.039(0.005)$ & $Y_{\text {fungicide }}=2.006-0.317 x+0.039 x^{2}$ \\
\hline 2011 & Untreated & $\begin{array}{r}1.894(0.059) \\
-0.112(0.056)\end{array}$ & $\begin{array}{l}-0.235(0.031) \\
+0.025(0.013)\end{array}$ & $0.027(0.004)$ & $Y_{\text {untreated }}=1.782-0.210 \mathrm{x}+0.027 \mathrm{x}^{2}$ \\
\hline 2011 & Fungicide & $1.894(0.059)$ & $-0.235(0.031)$ & $0.027(0.004)$ & $\mathrm{Y}_{\text {fungicide }}=1.894-0.235 \mathrm{x}+0.027 \mathrm{x}^{2}$ \\
\hline
\end{tabular}

\footnotetext{
a Subplot $\times$ subplot.
}

${ }^{\mathrm{b}} \mathrm{x}$ represents subplot position ( 1 to 7 , where $1=$ southernmost position). 

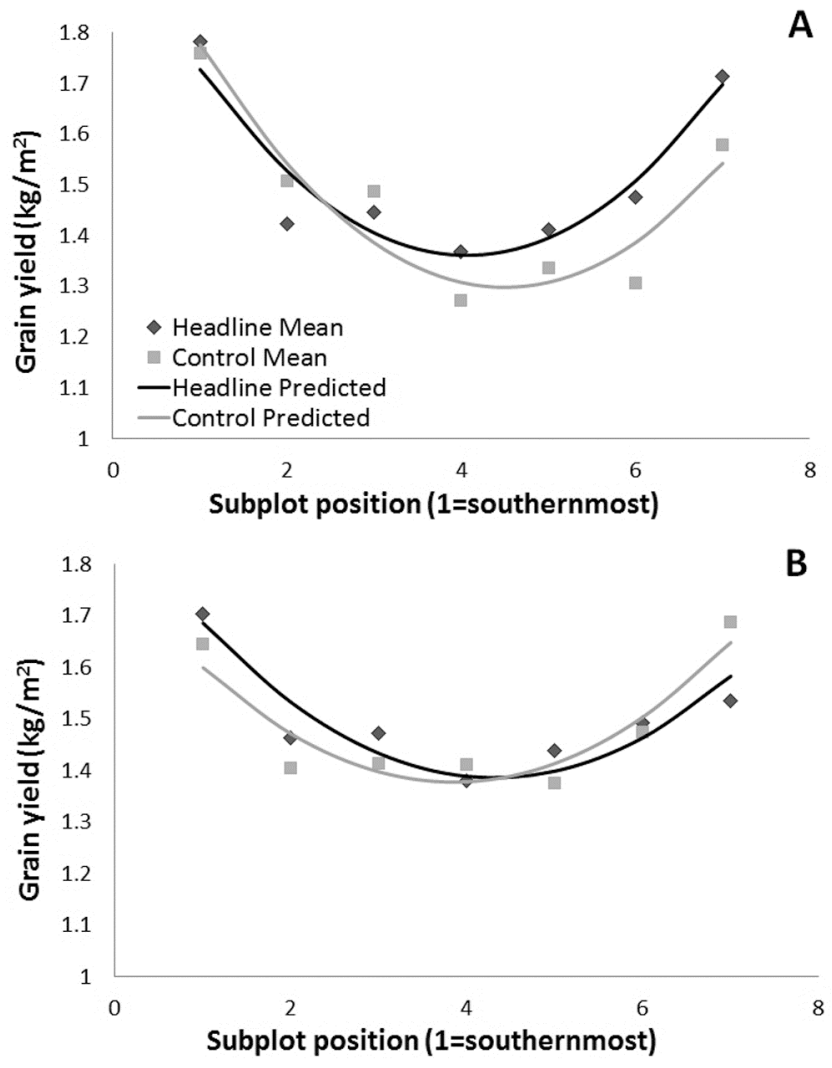

Fig. 2. Response curves for mean grain yield of corn over a south-to-north transect in fungicide-treated and untreated plots in 2010 (A) and 2011 (B). Regression equations for prediction lines are presented in Table 2.

alleys. We evaluated this hypothesis by using the regression equations in Table 2 to generate predicted yields for all seven subplot positions, and comparing the mean of these to the mean obtained using predicted yields from only the centermost three subplot positions. Predicted yields were lower when calculated based on the central three subplot positions only (Table 3). However, in comparing predicted yields from all seven subplot positions vs. the centermost three subplot positions, differences due to fungicide were less than $0.5 \%$ and therefore were considered trivial (Table 3 ).

Disease levels in both years were extremely low, due to low levels of primary inoculum and dry weather during much of the growing season. In untreated plots, severity of gray leaf spot on leaves subtending the primary ear was less than $0.2 \%$ at R5 in both years, and southern rust was below $0.7 \%$ and undetected in 2010 and 2011, respectively. Such extremely low disease severities were not thought to have influenced yield.

\section{Discussion}

The upward curvature of yield in subplots near and adjacent to the open alleys indicates that including plot ends in the harvest would result in overestimation of yield. This result is consistent with many years of agronomic field research $(1,3,7,10,15)$. However, our novel finding was an interaction of fungicide with subplot position, indicating that the estimation of the yield response from fungicide depended on position within the plot. Such an interaction raised the question as to whether including plot ends in an open-alley design could potentially bias the estimation of the yield response from fungicide. We concluded that this study did not provide support for this hypothesis. Assuming the central three subplots are most representative of crop response in a commercial field, we compared yield responses estimated from the central three subplots to those estimated using all seven subplots. Since no meaningful difference was observed between these estimates in either year of the study, we conclude that, in our experiments, the open-alley design did not bias estimates of yield effects of fungicide use.
Table 3. Predicted mean corn yield using all seven subplot positions vs. the centermost three subplot positions

\begin{tabular}{llcc}
\hline & & \multicolumn{2}{c}{ Predicted yield $\left(\mathbf{k g} / \mathbf{m}^{\mathbf{2}}\right)^{\mathbf{a}}$} \\
\cline { 3 - 4 } Year & Treatment & All seven subplots & Centermost three subplots \\
\hline 2010 & Untreated & 1.46 & 1.33 \\
2010 & Fungicide & 1.52 & 1.39 \\
Yield response from & & \\
fungicide & $3.6 \%$ & $4.0 \%$ \\
$2011 \quad$ Untreated & 1.48 & 1.39 \\
$2011 \quad$ Fungicide & 1.49 & 1.40 \\
Yield response from & & \\
fungicide & $0.8 \%$ & $0.9 \%$ \\
\hline
\end{tabular}

${ }^{a}$ Estimated yields obtained using regression equations presented in Table 2.

${ }^{\mathrm{b}}$ Calculated as $100 \times$ (yield of treated - untreated)/yield of untreated.

While the present study shows no indication of a design-related bias in estimating fungicide effects in corn, the fungicide $\times$ subplot effect observed in the present study suggests a need for improved trial design. Several solutions suggest themselves. One is to design field trials without open alleys, although this creates significant logistical problems when applying fungicides in a randomized, replicated design. Another potential solution might be to use longer plots and exclude plot ends from harvest (by end-trimming, for example). Such an approach might overcome alley effects due to interplant competition. However, many questions remain with respect to trial design for testing fungicide in corn. Small-plot, openalley trials may be unrepresentative of fungicide-treated crops in ways not yet understood. For example, if treatment with a $\mathrm{Q}_{0} \mathrm{I}$ fungicide improves crop tolerance to heat stress, such impacts might show up at the scale of large plots or commercial fields but not in small-plot trials with open alleys, because the latter might allow for air circulation around and through small plots to an extent not found in high-density commercial fields. Alternatively, if strobilurin fungicides produce reductions in canopy temperatures under water stress, such an effect might be lost in an open-alley, small-plot design.

In conclusion, our study does not lend support to the hypothesis that the open-alley design creates a bias in assessment of treatment effects due to foliar fungicides in corn. However, additional studies are called for, as the present study does not address all questions relating to trial design and assessment of fungicide benefits, particularly since results may be different under conditions of moderate to high disease pressure. Given the millions of hectares of corn now being treated annually with $\mathrm{Q}_{0} \mathrm{I}$ fungicides, often to obtain beneficial physiological crop responses, ongoing research on sound methodology for testing crop response to fungicide application is warranted.

\section{Acknowledgments}

Thanks to Kristen McQuerry and Dr. Constance Wood, of the Department of Statistics, University of Kentucky, for statistical consultations. Thanks are also expressed to Katie Russell, Ed Dixon, and James Dollarhide for assistance with execution of the field trials.

\section{Literature Cited}

1. Arny, A. C. 1922. Border effects and ways of avoiding it. J. Am. Soc. Agron. 14:266-278.

2. Bradley, C. A., and Ames, K. A. 2010. Effect of foliar fungicides on corn with simulated hail damage. Plant Dis. 94:83-86.

3. Boerma, H. R., Marchant, W. H., and Parker, M. B. 1976. Response of soybeans in maturity groups V, VI, VII, and VIII to end-trimming. Agron. J. 68:723-725.

4. Diaz-Espejo, A., Cuevas, M. V., Ribas-Carbo, M., Flexas, J., Martorell, S., and Fernández, J. E. 2012. The effect of strobilurins on leaf gas exchange, water use efficiency and ABA content in grapevine under field conditions. J. Plant Physiol. 169:379-386.

5. Grossmann, K, and Retzlaff, G. 1997. Bioregulatory effects of the fungicidal strobilurin kresoxim-methyl in wheat (Triticum aestivum). Pestic. Sci. 50:11-20.

6. Herms, S., Seehaus, K., Koehle, H., and Conrath, U. 2002. A strobilurin fungicide enhances the resistance of tobacco against tobacco mosaic virus and Pseudomonas syringae pv. tabaci. Plant Physiol. 130:120-127. 
7. Holman, E. M., and Bednarz, C. W. 2001. Alley effect on several cotton cultivars in small-plot research. Commun. Soil Sci. Plant Anal. 32:119-126.

8. Keisling, T. C., Walker, M. E., and Mullinix, B. 1984. Changes in the interpretation of irrigation fertilizer experiments caused by blank alleys. Commun. Soil Sci. Plant Anal. 15:903-907.

9. Khan, M. F. R., and Carlson, A. L. 2009. Effect of fungicides on sugar beet yield, quality, and postharvest respiration rates in the absence of disease. Online. Plant Health Progress doi:10.1094/PHP-2009-1019-01-RS

10. Probst, A. H. 1943. Border effect in soybean nursery plots. J. Am. Soc. Agron. 35:662-666.

11. Swoboda, C., and Pedersen, P. 2009. Effect of fungicide on soybean growth and yield. Agron. J. 101:352-356.

12. Vincelli, P., Fourqurean, D., and Dixon, E. 2013. Evaluation of fungicide application on disease intensity, stalk strength and yield in field corn, Trial II, 2011. Plant Disease Management Reports, 7:FC096.
13. Vincelli, P., Fourqurean, D., and Dixon, E. 2013. Evaluation of fungicide application on disease intensity, stalk strength and yield in field corn, Trial III, 2011. Plant Disease Management Reports, 7:FC095.

14. Weisz, R., Cowger, C., Ambrose, G., and Gardner, A. 2011. Multiple midAtlantic field experiments show no economic benefit to fungicide application when fungal disease is absent in winter wheat. Phytopathology 101:323-333.

15. Wilcox, J. R. 1970. Response of soybeans to end-trimming at various growth stages. Crop Sci. 10:555-557.

16. Ypema, H. L., and Gold, R. E. 1999. Kresoxim-methyl: Modification of a naturally occurring compound to produce a new fungicide. Plant Dis. 83:4-19.

17. Zhang, Y, Zhang, X, Chen, C., Zhou, M., and Wang, H. 2010. Effects of fungicides JS399-19, azoxystrobin, tebuconazole, and carbendazim on the physiological and biochemical indices and grain yield of winter wheat. Pestic. Biochem. Physiol. 98:151-157. 